\title{
RICARDO PIGLIA EN LOS LIBROS Y PUNTO DE VISTA. UN ANÁLISIS DE LA CRÍTICA PARA COMPRENDER LA FICCIÓN $^{1}$
}

\author{
Raquel Fernández Cobo \\ Universidad de Almería \\ Almería, España \\ rfc206@ual.es
}

\section{RESUMEN / ABSTRACT}

El presente artículo analiza la labor de agente cultural que Ricardo Piglia articuló en el marco de dos revistas clave de la segunda mitad de siglo XX (años 1969-1983) en Argentina, Los Libros y Punto de Vista, con el objetivo de argumentar y demostrar $r$ dos hechos importantes: en primer lugar, el éxito y la eficacia de las estrategias intelectuales que Piglia ha propuesto como parte de una generación -no exenta de contradicciones y polémicas- enmarcada bajo una Nueva Izquierda y, segundo lugar, la importancia del trabajo colectivo del grupo de ambas revistas para realizar una aproximación hermenéutica a la obra del escritor de Respiración artificial.

Palabras Clave: Revistas literarias, diarios, Nueva Izquierda, estética y política.

\section{Ricardo Piglia at Los Libros and Punto de VISTa. AN ANALYSIS OF THE CRITIQUE TO COMPREHEND THE FICTION}

This article analyzes the intellectual and critical work of Ricardo Piglia in the Argentine literary magazines Los Libros and Punto de Vista to demonstrate two important facts: first, the success and effectiveness of the intellectual strategies he has proposed as part of a generation framed under a New Left and as the creator of a colossal work of fiction. Secondly, the importance of

1 Este ensayo forma parte de la tesis doctoral titulada Ricardo Piglia: escritor, profesor y diarista. Una historia de la Educación Literaria como novela (Universidad de Almería, 2018). Pero ha sido revisado dentro del proyecto de investigación de la Universidad de Berna (Suiza), Literatura problemática. Problemática sociodiscursiva de textos en prosa de la Modernidad española (SNF/ FNS 100012_188957), dirigido por la Prof ${ }^{\mathrm{t}}$. Dra. Bénédicte Vauthier (2020-2024). 
the collective work of the group of both magazines to carry out a more exhaustive approach to the work of the writer of Respiracion artificial.

KEYWORDS: Literary journals, diaries, New Left Party, aesthetic, and politics.

Recepción: 16/03/2020

Aceptación: 30/09/2020

\section{INTRODUCCIÓN: LAS REVISTAS COMO AUTOBIOGRAFÍAS COLECTIVAS}

Durante la primera década de nuestra centuria, el interés por exhumar antiguas revistas y, al mismo tiempo, por publicarlas en ediciones facsímiles junto con numerosos estudios monográficos, ha demostrado cómo estas son un modo de leer y producir literatura que debe ser registrado dentro de una historia de la crítica. Las revistas literarias son enclaves culturales y espacios privilegiados donde se pueden leer, mejor que en ningún otro lugar, las polémicas y los debates de toda una época. Pero también podemos encontrar en ellas el génesis de una poética, de una escritura personal que, sin embargo, se construye bajo un lenguaje común y que puede leerse como la "autobiografía de la literatura" (Rosa, Artefactos VII). Tal es el caso de la obra de Ricardo Piglia en su relación con las revistas de la década de los setenta y los ochenta en la Argentina, junto con el trabajo de muchas editoriales de izquierda y las clases o grupos de estudio underground que construyeron su propio lenguaje como resistencia cultural ante la opresión del Estado. En este contexto surgieron un centenar de revistas ligadas a la revolución liberal y a la Nueva Izquierda ${ }^{2}$. En el caso que nos ocupa, fueron las revistas Los Libros y Punto de Vista las que dejaron una huella notable tanto en la vida como en la obra de Ricardo Piglia. Y, aunque es cierto que

2 Este resurgimiento y renovación de la izquierda llamado "Nueva Izquierda" se forma con el objetivo de realizar una auténtica crítica marxista del marxismo a través de la perspectiva de la escuela de Frankfurt, lo que dio lugar a una intensa relectura de Engels, Lenin, Trotsky, Mao Tse-Tung y el primer Marx, como consecuencia de la crisis de representación de los partidos tradicionales. Entre las revistas más destacadas de la década están El escarabajo de Oro (1961-1974), Pasado y Presente (1963-1965), Revista de Liberación (1963-1964), Desacuerdo (1972-1973), y también las revistas La Rosa Blindada, Táctica (1964) o Nueva Política (1965), Literatura y sociedad (1965), Los Libros (1969-1975) y Punto de Vista (19782008), entre otras. 
Piglia colaboró en Literatura y Sociedad ${ }^{3}$ y también con algunos escritos puntuales en El escarabajo de Oro y en Revista de Liberación, fue en aquellas otras revistas donde tuvo una participación más activa en la construcción ideológica de las mismas ${ }^{4}$.

Así, presentaremos un recorrido descriptivo por el trabajo de Piglia en Los Libros, ya que, como veremos, se trató de un trabajo muy colectivizado; mientras que en la segunda revista, Punto de vista, presentaremos un abordaje más argumental, puesto que sus publicaciones en este caso han sido puntuales reflexiones sobre Borges, Sarmiento o Hudson, que firmó como único autor, y quizá por ello han resultado más trascendentes para la crítica, que ha soslayado en gran medida la importancia del análisis de esta actividad dentro del proyecto pigliano en el cual debemos de considerar fundamentales las condiciones de producción de su literatura en relación al resto de campos: cultural, intelectual y político.

\section{LOS LIBROS: EL FERVOR REVOLUCIONARIO DE LOS SESENTA $^{5}$}

La revista Los Libros surge el 1 de junio de 1969, durante una situación de violencia generalizada por los enfrentamientos sociales con la derecha peronista. En palabras de José Luis de Diego: "los setentas se caracterizaron precisamente por una supresión casi total de las mediaciones entre el campo literario y el campo político" (¿Quién de nosotros 25). En este contexto, Los

\footnotetext{
Para un estudio desarrollado sobre el trabajo de Piglia en Literatura y Sociedad, véase Álvarez ("La revista") y Fernández Cobo ("Piglia en los 60").

Por ese motivo, el recorrido historiográfico de ambas revistas se hará en función de una selección muy limitada de textos que hemos considerado claves para cumplir el objetivo propuesto - una interpretación más exhaustiva de la obra de Piglia-. Somos conscientes de que el presente trabajo, por sus estrechas dimensiones, soslaya otras polémicas fundamentales en el campo literario argentino relacionadas con la obra de Piglia (véase De Diego, 2001).

Hemos podido contar para esta investigación con la fabulosa edición facsimilar de Los Libros, realizada por la Biblioteca Nacional de Argentina, cuyo director, Horacio González, incluye un prólogo en donde hace referencia a la importancia de la vida de los colaboradores de la revista. Además, se incluye un artículo que ha sido de gran ayuda para una historia de Los Libros, realizado por Patricia Somoza y Elena Vinelli, ambas amigas y compañeras de Ricardo Piglia.
} 
Libros ocupó un lugar privilegiado en la crítica literaria argentina. El primer número apareció en 1969, dirigido Héctor Schmucler -al que todos llamaban Toto- junto con un Ricardo Piglia que prefirió que su nombre quedara en la sombra. El número 29 marcará una segunda etapa en la revista, que será a partir de entonces dirigida por Carlos Altamirano, Beatriz Sarlo y Ricardo Piglia. La revista será caracterizada por una lucha antiacadémica y una creciente politización y "latinoamericanización", si se nos permite el término, con números especializados -sobre Cuba, Perú, Chile, etcétera-, en una línea de izquierda revolucionaria en la que plantearon objetivos y polémicas que no solo marcarán el desarrollo cultural e intelectual de los años venideros en la Argentina, sino que se perpetuarán en la ficción de Ricardo Piglia, como veremos más adelante.

En junio de 1969, Los Libros empieza a ser editada por la editorial Galerna, de Guillermo Schavelzon. Fundada y dirigida, como decíamos, por Héctor Schmucler, el cual importaba de Francia las ideas estructuralistas de Barthes, Lacan y Lévi-Strauss tomando como modelo La Quinzaine Littéraire, pero con una marca más vanguardista. Los libros, como La Quinzaine, pretendía intervenir en el mercado reseñando todos los libros que se publicaban durante un mes en la Argentina, de ahí el primer subtítulo d la revista: "Un mes de publicaciones en Argentina y el mundo". Así describe Piglia en sus Diarios su nacimiento en la escena cultural:

\begin{abstract}
Miércoles 16
[...] al final viene Héctor Schmucler de París; muy generoso, me propone hacer con él una revista estilo la Quinzaine en Buenos Aires. Es decir, una revista mensual que se ocupe de reseñar todos Los Libros que se publican en Argentina y que a la vez, como yo le propongo, actualice los debates sobre literatura y se oponga frontalmente a la crítica periodística y a los suplementos culturales (Un día en la vida 130 ).
\end{abstract}

Tal como se declara en el editorial del primer número, la revista tenía el propósito de "llenar un vacío" (Los Libros 1, 3), es decir, de crear un espacio nuevo, especialmente en el ámbito de la crítica literaria que se planteaba modernidad con la incorporación de la nueva crítica francesa. Así concluía el primer Editorial:

Se trata, pues, de crear un espacio que en el caso de Los Libros tiene un terreno preciso: la Crítica. Darle un objeto - definirla- y establecer 
los instrumentos de su realización, permitirán dibujar la materialidad con la que se pretende llenar el "vacío" de la recodada expresión de circunstancia.

Los Libros no es una revista literaria, entre otras cosas porque condena la literatura en el papel de ilusionista que tantas veces se le asignara. La revista habla del libro. Y la crítica que se propone está destinada a desacralizarlo, a destruir su imagen de verdad revelada, de perfección a-histórica.

\section{Los Libros, julio de 1969 (3).}

Cuando la universidad fue intervenida por el gobierno militar de Onganía en 1966, la actualización y apertura de la crítica tuvo que buscar espacios alternativos. Las revistas serán los espacios principales para difundir esa "nueva crítica" francesa, la cual apela a un instrumental que conforma nuevos discursos y saberes, entre los que están la antropología estructural, el psicoanálisis lacaniano, el marxismo althusseriano y gramsciano y, sobre todo, la lingüística que nos permite acercarnos a "lo concreto real de la obra (hecho de palabras) con un instrumento científico" (Rosa, "Nueva novela latinoamericana" 7) ${ }^{6}$.

A partir de este primer número, donde se presentaba a la nueva crítica, la revista tuvo siete años de vida y se publicaron 43 números más, distribuidos a Sudamérica, Estados Unidos y Canadá, aunque el circuito de distribución fue aumentando de manera progresiva, como indican los subtítulos ${ }^{7}$. Los temas y los autores tratados en la revista son recurrentes: Roberto Arlt, Gombrowicz, Bioy Casares, Cortázar, Manuel Puig, Tomás Eloy Martínez, Emilio Rodrigué,

6 En el artículo citado, Rosa reseña la obra de Jorge Lafforgue, Nueva novela latinoamericana (Paidós, 1969). La obra presenta una serie de ensayos sobre novelistas contemporáneos americanos realizada por los críticos que protagonizarán poco tiempo después la escena de la nueva crítica. Es, por tanto, un libro que presenta no solo una nueva novela sino una nueva crítica. Y, entre ellos, Ricardo Piglia colabora con su conocido ensayo sobre Puig: "Clase media: cuerpo y destino (Una lectura de La traición de Rita Hayworth de Manuel Puig)".

José Luis de Diego en su ensayo "Los intelectuales y la izquierda argentina” (2008) advierte que, si bien existe una continuidad durante los siete años que recorre Los Libros, es frecuente leer en las reseñas y en los artículos que se han escrito sobre la publicación que el número 29 marca una inflexión en sus historia: es posible hablar entonces de una primera etapa, identificable por la presencia de Schmucler en la dirección, y una creciente etapa -la de formato reducido-, con la presencia del trío en la dirección y caracterizada por una creciente politización en sus artículos (¿Quién de nosotros 410-11). 
Nestor Sánchez, Arguedas e, incluso, David Viñas. En los primeros ocho números de Los Libros aparecieron reportajes y traducciones de Marcuse, Sartre, Marx, Althusser y Chomsky, entre otros. El estructuralismo de LéviStrauss, junto con la ideología de Marcuse, ocupaban un lugar especial. En 1969, Los Libros funda el mito Gombrowicz de la mano de Germán García en la sección de "Presencias". García escribe una despedida en la que evoca la traducción colectiva de Ferdydurke entre bares y bebidas, cuando "Wiltold", como lo llamaban sus amigos, no conocía bien el idioma español. Con ello, Germán transforma la escena de su escritura en mito. García cierra su artículo diciendo: "ahora nos toca a nosotros mirarnos en Gombrowicz" (12). Hecho de exilios y traducciones, el mito sería también el símbolo de lo que pasaría después de 1969, en un clima de ebullición cultural y política que dominó los sesenta y los primeros años de los setenta. A partir de la segunda mitad de los setenta, muchos escritores, traductores y editores saldrían al exilio. Como señala Alejandrina Falcón, "en ese exilio, quizás, alguno haya recordado la frase profética de German García sobre Gombrowicz" (14). En esa condición, muchos autores buscarán en la condición de extranjero, en la marca extraterritorial, la definición del escritor argentino.

Durante los siete años que Piglia estuvo en la revista, se encargó de reseñar todos los libros que aparecen al final, en el apartado "Los libros". Además, escribió contados pero importantes artículos. Se encargaba, sobre todo, de la literatura norteamericana. En el número 1 (julio de 1969) redactó una reseña sobre la novela de Joseph Heller, Trampa 22 ("Heller. La carcajada liberal" 11), la cual hace patente la tradición anarquista que más tarde pondría en marcha en sus ficciones, sobre todo en El camino de Ida (2013), donde recoge, podemos decir, un canon estético anarquista: Tolstói, Conrad, Hudson -pero también Borges, Walsh y James en Blanco nocturno, o Joyce, Arlt y Macedonio en La ciudad ausente-.

En el número 11 (septiembre de 1970), Piglia publica "Nueva narrativa norteamericana". Para el escritor de Adrogué, los mejores novelistas actuales del panorama norteamericano son aquellos que "intentan trazar zonas de aislamiento en el interior de la estructura, espacios de resistencia y de oposición a la voracidad del sistema" (11). Es decir, aquellos que paradójicamente son antinorteamericanos y antiimperialistas. Entre ellos, destaca a Saul Bellow, Philip Roth, Bernard Malamud, de nuevo Joseph Heller, J. D. Salinger, Bruce Jay Friedman, John Barth y Thomas Pynchon. Todos ellos cuestionan los fundamentos económico-ideológicos de la superpotencia y denuncian el modelo de cultura de dominación. Droga, regreso a la naturaleza, violencia 
sexual y delirio son algunos de los temas refugio de estos novelistas y, a su vez, señalan claramente las preocupaciones y temas centrales en la obra futura de Piglia. Recordemos al personaje de Munk en El camino de Ida (2013) -podría perfectamente ser un personaje de las novelas de Saul Bellow, Joseph Heller o Bernard Malamud-: un personaje delirante que se va a vivir a la naturaleza e intenta, desde ese lugar, acabar con el sistema capitalista. La novela, en general, reclama una lectura paranoica que sepa encontrar las referencias escondidas en el lenguaje: Ida Brown utiliza el plural en su contestador telefónico, "Soy Ida Brown. Estamos ausentes y no puedo atenderlo" (84). Del mismo modo que Luca Belladona, en Blanco nocturno, "hablaba en plural cuando se refería a sus proyectos y realizaciones y en singular cuando se trataba de su propia vida" (221). Todos sus personajes utilizan el plural cuando hablan de su ideología y proyectos, del mismo modo que el grupo de Los Libros y Punto de Vista trabajaban desde una conciencia colectiva. Así, este artículo sobre los escritores norteamericanos se podría leer como un prólogo, un protocolo de lectura que nos permite manejar mejor la novela, sobre todo en cuanto Piglia plantea en El camino de Ida una teoría de la lectura colectiva como alternativa para alcanzar la verdad (véase Fernández Cobo "Nostalgia, utopía y complot")

En general, Los Libros propone acercarse a la materialidad del lenguaje y a la ideología que hay dentro del propio discurso, a la que solo podemos llegar acercándonos a su especificidad y a sus detalles ${ }^{8}$. En numerosas ocasiones los textos de los miembros respondían a polémicas internas, que solo ellos

8 Josefina Ludmer, al igual que Nicolás Rosa, también propone trabajar la obra desde la obra misma: "desde adentro y con el material mismo de la obra, de un modo que no podría aplicarse a ninguna otra", mostrando cómo se produce significación y se hace posible la construcción de un nuevo saber. En "La literatura abierta al rigor" (Los Libros 9, julio de 1970), Ludmer reseña la obra de Nicolás Rosa, Crítica y significación (Galerna), donde defiende a la obra de su amigo Rosa de las acusaciones de plagio que se discutieron en el interior de las reuniones de la revista; una polémica que quedó reflejada en algunas declaraciones de Piglia y en sus diarios. Ludmer señala cómo los artículos no siguen un orden cronológico, atendiendo al año de publicación de las novelas o la generación de los escritores, sino que el orden depende del significado que la obra tiene para el lector. Ludmer da cuenta del nuevo modo de hacer crítica en Rosa: analiza personajes, acciones, "lo que se narra y cómo se narra" (5), es decir, centrándose exclusivamente en la obra, en los modos y las formas de la narración. "El crítico trabaja desde adentro y con el material mismo de la obra, de un modo que no podría aplicarse a ninguna otra (esa es una 'prueba' de un buen análisis concreto); produce un saber nuevo al mostrar el modo de producción de su significación” (5). 
conocían y que vienen a afirmar lo que De Diego ha llamado una "crítica de control" (¿Quién de nosotros 27): una suerte de "crítica de la crítica" en la que los colaboradores se comentaban entre ellos hilando una red de intervenciones. Buscaban hacer teoría y no solo crítica, de modo que "el cruce entre vanguardia política y vanguardia estética no adopta en Los Libros la forma de debate ideológico sino la de un problema que debe resolverse en el interior de un discurso crítico" (De Diego, "Los intelectuales" 411), es decir, no recurriendo directamente a los modelos (psicoanálisis, marxismo, feminismo, etcétera), sino interrogando a los propios textos desde una posición localizada: desde dónde se lee, de qué texto se habla y qué se dice de él. Porque para ellos lo político en la literatura argentina es justamente lo que no se nombra pero está dentro del lenguaje.

A partir del número 8 se hablará por primera vez de una película y se ampliarán los horizontes con el subtítulo "Un mes de publicaciones en América Latina", indicando su "latinoamericanización", lo que también señala el ingreso de una gran nómina de editoriales mexicanas, venezolanas, chilenas y argentinas con un eficiente sistema de distribución que abarca América Latina, Estados Unidos y España. Se incorporan corresponsales y colaboradores de varios países de la región y, gracias a ello, muchos artículos pueden contar problemáticas sociales como la guerrilla en Perú o el testimonio de tortura en los años de la dictadura de Brasil. Con ello, los temas se van haciendo progresivamente más políticos y cada uno de los números va dedicado a un país. Leemos titulares como "Los intelectuales y el poder", "El nacionalismo popular" o "Socialismo sin Marx", entre otros. También se incluye un reportaje a Chomsky sobre lingüística y política.

El número 15/16 (febrero de 1971, número doble especial), dedicado a Chile, fue el punto de inflexión que produjo ese énfasis político en la revista: era la época del triunfo de la Unidad popular de Allende en Chile. A partir de este número, en Los Libros comenzarán a dominar los artículos analíticos sobre cuestiones políticas y sociales. Como han señalado Somoza y Villeli (9) siguiendo las declaraciones de Piglia, la publicación girará, a partir de ahí, en torno a dos ejes fundamentales: uno vinculado con la nueva crítica, la difusión de nuevas corrientes teóricas -como dijimos, principalmente provenientes de Francia- y su relación con la política; y el otro relacionado con el rol de los intelectuales en un contexto político que se desplegaba de modo vertiginoso. Se trataba de una época en la que la figura del escritor, el intelectual y el militante estaban difusas y se discutía principalmente sobre la posición que debían tomar ante un debate cada vez más dicotómico: la 
literatura o las armas. De ahí la imperativa pregunta que aparece en Respiración artificial: en este contexto donde la violencia salpica a la literatura e irrumpe en ella como lo hizo en Operación Masacre de Walsh, “¿Quién de nosotros escribirá el Facundo", se pregunta Piglia. ¿Quién de su generación será entonces capaz de aunar literatura y política como lo hizo el libro fundacional de literatura argentina?

En el número 22 (septiembre de 1971), la revista adquiere otro subtítulo, "Para una crítica política de la cultura", junto con la ampliación del consejo de dirección. Además de Schmucler, se sumarán Ricardo Piglia y Carlos Altamirano. Este "triunvirato" dura apenas dos números (23 y 24), pues en el número 25 el consejo se amplía a seis miembros con la suma de Beatriz Sarlo, Germán García y Miriam Chorne. Estos cambios en la dirección revelan ciertas polémicas internas entre sus miembros colaboradores con respecto a la orientación que debía tomar Los Libros en relación con el debate sobre la posición de los intelectuales en los proyectos de transformación revolucionaria.

En ese mismo número se incluye "De la traición de la literatura", reseña que Ricardo Piglia hace de Ajuste de cuentas (1972), libro de cuentos de Andrés Rivera. Piglia reseña libros que siguen la línea que postula Rosa en "La crítica como metáfora", de manera que toda la eficacia del relato reside en lo no dicho, en aquello que se oculta. La literatura política y el lenguaje son el tema de la obra y "sin embargo el lenguaje del narrador nunca es el de la política, sino el de una sexualidad cargada con todas sus compulsiones, sus resistencias, sus coartadas" (Piglia, "De la traición" 7). Señala otras obsesiones importantes del libro, como la pérdida de la mujer, la traición y el juego de espejos del protagonista, es decir, la identidad y el delirio: temas fundamentales de la poética de Piglia. Obsesiones que convierten al conjunto de relatos en un todo único. Pero lo verdaderamente importante de las intervenciones de Piglia en la revista son las conexiones que se dan entre las obras que reseña y su futuro trabajo como escritor. El crítico Edgardo Berg ya señaló que su escritura funciona "como una máquina de repetir y conectar los grandes nombres propios de la literatura. Generando, de este modo, filiaciones y alianzas tácticas. [...] La máquina narrativa de Piglia ejerce un uso estratégico de la tradición, una política anarquista en micro que subvierte los principios de propiedad y paternidad textual" (129).

Para el número 29 (marzo-abril de 1973), Sarlo, Altamirano y Piglia, los tres de inclinación maoísta por aquel entonces, toman el consejo de dirección. Con ello, la publicación cambia nuevamente su subtítulo a "Para una crítica política de la cultura". Como dijimos, en sus inicios la revista funcionaba 
como un colectivo y expresaba la voluntad de encontrar un método riguroso de análisis para la literatura. Pero las diferencias ideológicas entre sus integrantes fueron manifestándose a medida que los cambios políticos del país se aceleraban a una velocidad vertiginosa. Piglia registra estas disputas desde los comienzos de la revista en sus Diarios de 1969:

Domingo 12 de octubre

Los conflictos con la revista se agravaron, discusiones con Toto, Willie, etc., por los intentos de reordenar la revista dejándonos afuera. Me escuché a mí mismo levantando encendidas diatribas morales que surtieron poco efecto. Todo sigue igual y ahora soy yo quien quiere abrirse (después de cobrar el sueldo de este mes para cubrir el déficit de la mudanza) (Los años felices 158).

Con el triunfo de Allende en Chile, la izquierda comienza a dividirse, lo que tiene graves consecuencias. Algunos miembros se radicalizaron provocando, a su vez, cambios en el proyecto inicial de la revista. Ante esta situación, la literatura y la crítica parecen perder su lugar cardinal, la política parece ganar la partida. Así, desde el número 29 hasta el número 44, el grupo Los Libros busca hacer una crítica a la Unión Soviética y vemos cómo Mao Tse-Tung y la Revolución Cultural Rusa van tomando protagonismo en las páginas de la publicación. Ya en el número 25 (marzo de 1972) de Los libros, Ricardo Piglia había publicado una reseña de Charlas en el foro de Yenan sobre arte y literatura (ediciones Marxismo de hoy, 1972), de Mao Tse-Tung, a la que tituló como "Mao Tse-Tung. Práctica estética y lucha de clases". Por aquel tiempo, un joven Piglia de apenas treinta y un años formaba parte del Partido Vanguardia Comunista, que veía en el pensamiento de Mao Tse-Tung la mejor alternativa posible para la problemática que presentaba la vanguardia estética y la vanguardia política.

La política (escribe Mao) no equivale al arte, ni una concepción general del mundo equivale a un método de creación y de crítica artística. Al no reducir la producción estética (ni tampoco la crítica a la política o la ideología, Mao le reconoce toda su eficacia a partir de su forma específica y de su inteligibilidad propia y le estructura un espacio singular en el conjunto de su teoría sobre la articulación de la práctica social (Piglia, "Mao Tse-Tung" 22). 
A lo largo de las intervenciones que hace Piglia en Los Libros intentamos dar cuenta de su esfuerzo y dedicación por armar una teoría marxista de la literatura que sea capaz de distinguir entre el "contenido político" y el "contenido artístico" como dos instancias diferenciadas de la obra que, aunque permiten dos modos de lectura distintos, son al mismo tiempo dependientes, lo que no significa (como ha pretendido Lukács) que una práctica literaria traicione y haga olvidar la ideología: una obra no es buena a pesar de su ideología, sino con ella, en el procedimiento mismo de hacerla visible, al exhibirla como un momento material de la producción literaria (Piglia, "Intelectuales y revolución" 25).

En el número 29 (marzo-abril de 1973), Piglia publica su afamado ensayo sobre Arlt, "Roberto Arlt: una crítica de la economía literaria". Su tesis principal es presentar la lectura como algo que está situado geográfica y contextualmente -"el texto intenta definir el lugar desde donde se quiere ser leído" (22)- y que la literatura está ligada al circuito de la cultura por medio de la demanda y circulación, como cualquier otro producto de mercado, con su propio valor económico. La forma y el estilo del texto dependen también de una economía de mercado. Piglia lee en Arlt una crítica económica de la literatura: "es el precio quien decide el valor y esta inversión viene a afirmar que no hay un sistema de valor independiente del dinero" (24).

El número 35 (mayo-junio de 1974) está dedicado a China. La revista abre con un artículo de la pluma de Ricardo Piglia, titulado "La lucha ideológica en la construcción socialista". Los temas centrales son la práctica social, la división de trabajo y de clases y la teoría marxista. Fue escrito después de su periplo de cinco meses por China, París y Londres. A su vuelta, las tensiones en Los Libros aumentan tanto por la atmósfera de violencia que rodea el contexto político y social de la época, como por las contradicciones políticas cada vez más presentes entre sus miembros.

Así, Piglia abandona Los Libros en 1975. Se despide como miembro de la revista en el número 40 (marzo-abril de 1975), publicando sus canónicas "Notas sobre Brecht", reseña de su libro El compromiso en literatura y arte (Ediciones Península, 1974). Para el escritor argentino, Brecht representa la tentativa de fundar en la práctica una teoría marxista de la producción literaria y, a la vez, de definir los elementos de una crítica científica con una metodología definida, capaz de inscribir los resultados de esa práctica en la lucha de clases, a través de los distintos contratos sociales que se dan entre el texto y el lector, pues se entiende que cada clase tiene su "literatura": "su estética" y "su política”. Por ello, la publicación de los tres tomos de escritos 
de Brecht sobre arte y literatura es, sin duda alguna, como afirma Piglia, "el acontecimiento más importante en la crítica marxista desde la publicación de los cuadernos de Antonio Gramsci" ("Notas" 4), de quien, por otra parte, el pensamiento de Brecht se encuentra en la antítesis. Brecht es importante, nos dice Piglia, no solo porque nos permite reconocer que hay una alternativa a la estética estalinista (y a la comunista de los años treinta a los cincuenta), sino porque, además, Brecht reconstruye una teoría del arte centrada en las condiciones de producción de la literatura.

El último número de Los Libros se publica en febrero de 1976, casi un año después de la partida de Ricardo Piglia y días antes de producirse el golpe de Estado del 24 de marzo. La revista dejó en 1976 el mismo vacío en la escena cultural que vino a cubrir en 1969.

\section{PUNTO DE VISTA: LA CRÍTICA UNDERGROUND COMO RESISTENCIA $^{9}$}

La dictadura militar autodenominada "Proceso de Reorganización Nacional" se instauró en 1976 y continuó hasta 1983. En 1977, los dirigentes de Vanguardia Comunista (VC), Elías Semán, Rubén Kriscautzky y Abraham Hochman, se reunieron con Beatriz Sarlo, Ricardo Piglia y Carlos Altamirano para comenzar de nuevo a construir una revista de izquierda. En medio de un contexto de persecución, exilio, desaparición y asesinato de intelectuales de izquierda; cierre de revistas y periódicos; intervención de universidades y otras instituciones donde fuera posible la crítica surge Punto de Vista, subtitulada "Revisa de cultura", con el objetivo de continuar con el proyecto de Los libros, aunque pronto la nueva revista superaría los límites de la primera y se consagraría como la revista más importante del campo intelectual en Argentina. Bajo la dictadura, Punto de Vista fue comercializada de manera casi clandestina por sus integrantes. En marzo de 1978, se publicó el primer número y, días más tarde, los tres dirigentes de VC, Semán, Kriscautzky y Hochman, desaparecieron. Ricardo Piglia dedica su primera novela, Respiración artificial (1980), a ambos: “a Elías y Rubén, que me ayudaron

9 Para el análisis de los números de esta revista hemos consultado la edición digital que ha sido recogida por el proyecto Bazar Americano, dirigido por Ana Porrúa: http://www. bazaramericano.com/punto.php [Consultado el 3 de febrero de 2017]. 
a conocer la verdad de la historia”. A partir de ese suceso, la revista perdió el apoyo económico y tuvo que continuar su circulación de modo totalmente underground, en oposición a la dictadura militar, sin estar relacionada con ninguna institución. Desde sus primeros números hasta el número 12 (juliooctubre de 1981) -cuando su proyecto literario parece inclinarse hacia un terreno mucho más político-, los artículos se escribieron con velados sistemas de alusiones y fueron firmados con seudónimos, como muestra del peligro que suponía la práctica intelectual. Así es cómo Ricardo Piglia comienza a escribir bajo el seudónimo de Emilio Renzi.

Tal como señaló Roxana Patiño (11), Punto de Vista lleva adelante dos importantes operaciones: una puesta al día de la crítica, donde sobre todo la figura de Raymond Williams será central, y, paralelamente, una redefinición de las líneas de la tradición literaria argentina. En el número 12 aparece en la revista lo que puede denominarse el primer editorial, junto con la primera formación del consejo de dirección ${ }^{10}$ :

Encerrada en los límites de la amenazada producción material, la ciega torpeza del censor, el oscurantismo ultramontano de la universidad estatal, la cultura argentina, para construirse, debe hacerlo en la superación de estos obstáculos: [...] frente a la censura política, los intelectuales hemos imaginado, en estos años, formas y espacios nuevos para la discusión y circulación de ideas, posiciones, prospectivas (Punto de Vista, Editorial 2).

Allí justifican el nombre y los intereses de la publicación, así como un balance de los doce números anteriores en los que, dicen, "se propusieron defender, en la práctica, el espíritu crítico y nuestro derecho a la divergencia. Esto es, reivindicar la libertad de pensar, escribir, difundir ideas diferentes: el derecho al punto de vista" (ibid.). Además, anuncian esa redefinición y

10 A partir del número 12 y hasta el número 15, el consejo de redacción estuvo integrado, como hemos afirmado, por Carlos Altamirano, Ricardo Piglia, Beatriz Sarlo y Hugo Vezzetti. Piglia abandona Punto de Vista en el número 16, del año 1982 y, a partir de ahí, se incorporarán Hilda Sábato, José Aricó y Juan Carlos Portantiero, los cuales en el exilio habían formado parte de la revista Controversia. Finalmente, en el número 53 nos encontramos con un consejo asesor integrado por Raúl Beceyro, Jorge Dotti, Rafael Filippelli, Federico Monjeau y Oscar Terán. 
relectura de la tradición literaria argentina, como señalaba Patiño, en la que se reconocen y construyen su propio linaje:

Existe una tradición argentina que los que hacemos Punto de Vista reconocemos: una línea crítica, de reflexión social, cultural y política que pasa por la generación del 37, por José Hernández, por Martínez Estrada, por FORJA, por el Grupo Contorno. Descubrimos allí no una problemática identidad de contenidos, sino más bien una cualidad intelectual y moral (ibid.).

Ricardo Piglia solo formó parte de Punto de Vista durante su primera etapa (1978-1983), representada por la época más oscura de la dictadura. Por diferencias ideológicas con sus compañeros sobre el gobierno de Raúl Alfonsín, Piglia abandona la revista en 1982, presentando su última colaboración en el número de agosto-octubre. El resto de los miembros -si bien no eran de origen radical-miró con buenos ojos el alfonsinismo. Lo más característico de esta primera etapa de la que formó parte Piglia estaba marcado por el estrecho margen que la dictadura dejaba a la libertad de expresión. En sus números se cuida de hacer juicios sobre la dictadura y encontramos, básicamente, análisis sobre las obras de Sarmiento, Martínez Estrada o la generación de Contorno y Sur ${ }^{11}$.

\section{LAS PRIMERAS RELECTURAS DE BORGES}

En la segunda etapa de Punto de Vista, la reflexión pasa de Sarmiento a Borges de manera más explícita, pero incluso en esa primera etapa en la que

11 Publican en abril-julio de 1983 un dossier sobre Sur. También encontramos el interesante artículo de Sarlo, "Los dos ojos de Contorno" (Punto de Vista 13). Sarlo explica cómo dicha revista se encargó de construir la imagen de Sur como una revista ausente de compromiso, ecléctica y extranjerizante. Pero Punto de Vista interesada, como decíamos, en dos líneas que definieran la tradición argentina: lo local y lo universal -o lo extranjero, sería más acertado decir-, supo leer en Sur una estrategia que hacía posible, en una época de absoluta represión y censura, armar un discurso nacional a través de la voz del otro: la voz extranjera. Si repensar la izquierda no significa abandonar todas sus posiciones, sino redefinirlas y modularlas, las relecturas de Borges - parafraseando a Pagni- aparecen en el momento de repensar los postulados de una modernidad cuya especificidad consiste en ser periférica (Pagni 463). 
prevalece Sarmiento junto con otros escritores europeos, se publican los artículos sobre Borges más sobresalientes. Piglia publica "Ideología y ficción en Borges" (marzo de 1979) ${ }^{12}$ en el quinto número de la publicación y, con ello, funda la lectura izquierdista de Borges que todavía hoy día prevalece en uno y otro lado del Atlántico. Piglia lee la ficción del origen en Borges como una narración genealógica: la ficción familiar del linaje materno de sangre, "descendiente de fundadores y de conquistadores" ("Ideología" 4), y el linaje paterno "de tradición intelectual, ligada a la literatura y cultura inglesa" (ibid.), ambas como metáfora e interpretación de la cultura argentina en la que coexisten sin resolverse las contradicciones del mito familiar: la discordia entre las armas y las letras; entre la civilización y la barbarie:

Esta ficción familiar es una interpretación de la cultura argentina: esas dos líneas son las dos líneas que, según Borges, han definido nuestra cultura desde su origen. O mejor: esta ficción fija en el orden y en el núcleo familiar un conjunto de contradicciones que son históricas y que han sido definidas como esenciales por una tradición ideológica que

12 Quizá la relectura que más ha cristalizado en Argentina sobre Borges fue la realizada por Beatriz Sarlo, la cual fue desarrollada más ampliamente décadas más tarde, en el ensayo Borges: un escritor en las orillas (1993). Sarlo escribió para el número 11 de Punto de Vista "Sobre la vanguardia. Borges y el criollismo" (marzo-junio de 1981). En este texto, Sarlo descubre la importancia de la poética del criollismo urbano de vanguardia que construyó la revista Martín Fierro (1924-1927), no solo como antítesis de la estética de Boedo, sino también como síntesis entre la construcción formal y el populismo urbano, que tiene en Borges su máximo representante. También en el número 16 (noviembre de 1982), aparece "Borges en Sur: un episodio del formalismo criollo", escrito también por Beatriz Sarlo. En él, la catedrática de Sociología de la Literatura analiza el lugar marginal, o por lo menos lateral, que los textos de Borges tienen en los primeros números de la revista Sur. "Ajeno a las preocupaciones que definen la revista" (6), Sarlo se sirve de esa distancia para acercar a Borges estratégicamente a Shklovski y a la teoría del formalismo ruso, en cuanto que ambos buscan definir la propiedad esencial de toda literatura. A Borges, sin haber leído a Shklovski -afirma Sarlo-, le preocupaba la manera en que percibimos el valor poético de la obra artística. "Percibir - dice Sarlo- lo que la mirada imprecisa de la cotidianidad ha sepultado" (4) y, después, hacer de ello un mecanismo textual. La cuestión central en ambos teóricos de la literatura, podemos decir en este caso, será entonces la literatura como práctica (4). Desde esta perspectiva, Borges incorpora textos marginales, se preocupa por relatos menores como el género policial y centra las preocupaciones del escritor en el modo en que se construyen los textos, es decir, "en cómo leer, y, en consecuencia, cómo escribir" (6). La "literalidad", concepto que tanto preocupó a los formalistas rusos, reside, nos viene a decir Sarlo -y también Borges- en el modo en que leemos el texto. 
se remonta a Sarmiento. Así, podemos registrar, antes de analizarlas en detalle, las contradicciones entre las armas y las letras, entre lo criollo y lo europeo, entre el linaje y el mérito, entre el coraje y la cultura (Piglia, "Ideología" 4).

Y continúa más adelante:

El único punto de encuentro de ese sistema de oposiciones es, por supuesto, el mismo Borges, o mejor, los textos de Borges. En "la discordia de sus dos linajes" la obra se inscribe en una doble filiación que Borges resume al definirse (en el prólogo a uno de sus primeros libros, El idioma de los argentinos, 1928) como "enciclopédico y montonero". El culto al coraje y el culto a los libros que dividen su obra a la vez temática y formalmente no son otra cosa que la transcripción de ese antagonismo (ibid.).

Borges, a través de la lectura de Piglia, se constituía como la figura emblemática que representaría la ideología de la propia revista, pues en su obra se puede leer ese puente entre la cultura local y la cultura extranjera. No obstante, Piglia se cuidó de advertir que "esta forma ideológica no debe ser confundida con las opiniones políticas de Borges" ("Ideología" 6). La política, dice Piglia, determina la ideología, pero los elementos básicos que construyen la narración de Borges, esto es, la contradicción entre el linaje de sangre y el literario, se mantienen en toda su obra. Entonces, Piglia alienta al lector a estudiar "qué forma literaria hace posible integrar ese conjunto de contradicciones, o mejor, analizar de qué modo la transformación de ese material ideológico determina las particularidades de su escritura de ficción" (ibid.). Con ello subraya, desde una lectura marxista centrada en el análisis de las propiedades que hacen posible la escritura, el uso paródico y apócrifo de la literatura como estructura fundamental de la literatura borgeana, pero también como características resultantes de sus propias condiciones de producción.

Desde su trabajo como crítico, Piglia también realiza la estrategia borgeana, podríamos decir, de hablar de escritores extranjeros para cruzarlos con la tradición nacional. En el primer número de la publicación, podemos leer una reseña firmada por Emilio Renzi sobre Allá lejos y hace tiempo (1918), de G. E. Hudson. El provocador título de la reseña, "Hudson: ¿Un Güiraldes inglés?", apunta al modo en que la tradición argentina asimila la tradición extranjera a través de la traducción. La traducción, digamos, elimina el contexto y las condiciones de producción de la obra literaria y las pone en el mismo 
lugar, obligando al lector a leerlas del mismo modo: leer Allá lejos y hace tiempo del mismo modo en que leemos Don Segundo Sombra de Güiraldes. Piglia está atento a la manera equivocada en que la crítica lo ha interpretado como "un escritor argentino que desarrolla su obra en Europa" cuando, en realidad -nos dice-, es justo al revés. ¿Cuáles han sido las condiciones de producción de la literatura de Hudson? Esa sería la pregunta que trata de responder Piglia en su reseña. Hudson es, como definiría Sarmiento, "el europeo aclimatado en el Plata", es decir, el europeo que contradictoriamente cristalizaba la figura del intelectual argentino. Paul Groussac, dice Piglia, es el caso más representativo "porque sin duda el intelectual del 80 por excelencia es Groussac y no Cané, ni Mansilla, ni Wilde" ("Hudson" 23). Y, aceptado esto, Hudson sería también un intelectual argentino porque "es un europeo que escribe para europeos" y se define como escritor inglés, nacido y educado en las colonias inglesas que intentan preservar su cultura. "Como Kipling, Hudson utilizará su experiencia en esos lugares exóticos para elaborar una literatura a tono del lector europeo de la época" ("Hudson" 24). Hudson fue apropiado por la cultura argentina porque su estética naturalista se convirtió en una ideología básica del momento que venía a romper -y a invertir- el clásico dilema entre civilización y barbarie:

Momento clave en nuestra historia intelectual, se produce una inversión en la tradicional dicotomía entre civilización y barbarie. Porque si desde Sarmiento, Echeverría y Alberdi la barbarie había sido el desierto, la pampa, el primitivo mundo rural en guerra con la ciudad y con la civilización, hacia fines de siglo la ciudad, invadida por los inmigrantes, asolada por "los bajos intereses materiales" y por las luchas sociales, pasará a ser la metáfora negativa y hostil de una sociedad en transformación en la que están en peligro las pautas tradicionales $(i b i d$.).

La obra de Hudson estaba en el lugar y momento perfecto para ser traducida y apropiada por la cultura argentina. En este sentido, Hudson -o el polaco apócrifo Gombrowicz, por recordar el mito que Germán García funda en Los Libros y que Piglia nos recuerda también en su reseña-, no es un escritor argentino, sino "un europeo aclimatado en el Plata" y, por ello mismo, representa mejor que ningún otro la literatura argentina. 


\section{UNA POÉTICA DE LA ANALOGÍA Y LA ELIPSIS PARA RECONSTRUIR LA IZQUIERDA}

Como señala Piglia, Punto de Vista toma de Sarmiento el procedimiento de transformar las ideas europeas para que se adapten a la realidad nacional. Del mismo modo, la crítica ha señalado la elipsis y la analogía como recursos fundamentales de la obra de Piglia". Así, en sus "Notas sobre Facundo", publicadas en el número 6 de Punto de Vista (marzo-junio de 1980), apela al modo en que Sarmiento traduce la frase que abre Facundo: "On ne tue point les idées se transforma en $A$ los hombres se los degüella, a las ideas no. En el proceso de la traducción la frase se nacionaliza y pasa a ser, de hecho, un texto de Sarmiento" (Piglia, "Notas" 16). Por este motivo, Sarmiento y después Borges - por su evidente cruce con el escritor de Facundo a través de la cita apócrifa-son los escritores que marcan la tradición izquierdista de la revista. Williams y Hoggard aportan el andamiaje teórico-metodológico, pero Sarmiento y Borges llevan a la práctica literaria el juego del manejo y la apropiación de esa cultura europea. Tal es así, afirma Piglia, que la literatura argentina se inaugura con una cita en francés que marca la oposición entre civilización y barbarie condensada "en el contraste entre quienes pueden y quienes no pueden leer esa frase (que es una cita) escrita en otro idioma" ("Notas" 15). Y continúa: "Gesto profético, encierra una retórica y un programa: que esa diferencia se haya puesto en el manejo del francés define una de las claves de la literatura argentina" (ibid.). El francés, la lengua de la civilización y los ilustrados del siglo XVII, corroída en su traducción por la barbarie, que hace un "uso salvaje de la cultura" (Piglia, "Notas" 17) al emplear una cita errónea, falsamente atribuida a Fortoul, cuando fue tomada de Diderot -"No se fusilan ni degüellan las ideas"-.

El acentuado contenido político de la cita y del modo de transgredir el francés en su traducción no merecería más explicación por su obviedad, pero sí es interesante inferir en cómo Piglia señala, sutilmente, en un apartado de sus notas llamado "analogías", un mecanismo de Sarmiento del que él mismo se apropia como el mecanismo que mejor define su crítica. Así, dice Piglia: "Para Sarmiento saber es descifrar el secreto de las analogías: la semejanza es la forma misteriosa, invisible que hace visible el sentido. La

13 Véase el clásico estudio de Fornet (El escritor y la tradición) y el artículo de De Diego ("La narrativa de Ricardo Piglia"). 
cultura funciona sobre todo como un repertorio de ejemplos que pueden ser usados como términos de la comparación" ("Notas" 17). Mutatis mutandis: Piglia proclama un lector que descifre el sentido de los textos buscando el secreto que se esconde detrás de la comparación y semejanza que permiten "enlazar y asimilar situaciones, sociedades y épocas distintas" ("Notas" 18). Recordemos que, en Respiración artificial, Tardewski afirma que "ya nadie sabe leer. Porque para saber leer hay que saber relacionar" (206). También Croce, personaje de Blanco nocturno, se sumará a esa creencia cuando afirme que "la comprensión de un hecho consiste en la posibilidad de ver relaciones. Nada vale por sí mismo, todo vale en relación con otra ecuación que no conocemos" (265).

Con estas palabras iluminadoras, Piglia cierra sus "Notas sobre Facundo":

Los puntos de comparación pueden extenderse al infinito y cerrarse sobre sí mismos. Todo se parece a todo, pero a la vez se diferencia. Analogías encadenadas y vacías, fundadas en la semejanza y en la diferencia, se encuentra ahí un ejemplo de lo que podríamos llamar una forma figurada de la dialéctica. El misterio y la fascinación de las analogías irrealiza el texto y al mismo tiempo lo clausura. En este procedimiento, que es el fundamento de su ideología, debemos buscar la base para analizar el carácter literario de Facundo [y de la obra de Piglia, podríamos añadir] (18).

En este sentido, y continuando con la línea de Los libros, Punto de Vista "no se trataba de una importación de ideas sino de un diálogo. No era tanto una política editorial como una línea de pensamiento" (Oubiña párr. 11). Y esta línea de pensamiento puede vislumbrarse en la ficción de Piglia en varios elementos. Uno de ellos, quizá el más obvio y estudiado, ha sido el de las relaciones intertextuales de sus personajes y de sus propios textos. Como ha señalado Fornet, "casi todos los personajes se definen no solo por las relaciones que establecen con sus semejantes y con el entorno, sino también con determinados textos. Estas relaciones entrañan siempre una manera de interpretar o de asumir la historia" (90). Así, existen dos estrategias principales en la narrativa de Piglia que Sarlo señaló expresamente en un artículo como la idiosincrasia de la revista: por un lado, la refutación de la mímesis como forma única de representación (cf. Respiración artificial, La ciudad ausente y Prisión perpetua), y, por otro lado, pensar la escritura como "una de las maneras de entender la historia", y de vislumbrar la historia desde un "sistema 
de representación que se haga cargo de la complejidad, la discontinuidad y la problematicidad de lo real" (Sarlo, "El saber del texto" 45-54). De este modo, las estrategias de la crítica -en este caso Los libros-, como vemos, presentan una fuerte vinculación con los temas y preocupaciones expresados en la obra Piglia. Sarlo ("El saber del texto"; "Intelectuales") y José Luis de Diego (¿Quién de nosotros) han señalado que el recurso de la elipsis fue una de las características principales de la narrativa argentina durante la dictadura militar. Como explicará Piglia años más tarde de su trabajo en la revista, "nosotros, los marxistas -si me perdonan ese nosotros-pensamos el presente como historia. No nos podemos imaginar un presente que no tenga detrás o que no actualice la historia" (Años de formación 122). También en sus novelas las elipsis son un recurso fundamental que han estudiado críticos como Berg, Garabano, Fornet o De Diego. En su caso, la elipsis funciona como un enigma que el lector debe resolver a través de las asociaciones durante el proceso de lectura. De esta forma, el secreto en sus textos es más bien una elipsis lingüística: juega con lo que no se sabe o no se puede saber, puesto que es la única manera de contar la historia en la oscura época de la dictadura.

En el caso de las revistas, también la discusión política se encauzaba en "clave literaria", a través de la metáfora y la elipsis, tal y como sucede en la clásica conversación entre Renzi y Tardewski de Respiración artificial. De esta manera, la producción crítica y la producción artística de cada uno de los miembros se engloba dentro de un proyecto común, encerrado en sí mismo y endogámico.

\section{CONCLUSIONES: "LA ÉPOCA DE LA CRÍTICA DE LA CRÍTICA CRÍTICA"}

El análisis de su trabajo como crítico en dichas revistas culturales pretende remarcar una época altamente significativa en términos culturales y políticos que deja sus huellas en la poética de Ricardo Piglia. Hasta sus últimos días, siguió leyendo y entendiendo la crítica a la postre de los ideales que ellos, los amigos que conformaron Los Librosy Punto de Vista, habían construido y fundado. Y es por ellos que el plural predomina como sujeto de la enunciación en los diálogos de sus novelas, puesto que inserta en su ficción los diálogos de la crítica: 
Mis viejos amigos de Buenos Aires habían hecho lo mismo: leían Guerra de guerrilla, un método, de Ernesto Che Guevara, y se alzaban al monte. Leían ¿Qué hacer?, de Vladimir Ílich Uliánov, Lenin, y fundaban el partido del proletariado; leían los Cuadernos de la cárcel de Gramsci y se hacían peronistas. Leían la obra de Mao Tse-Tung e inmediatamente anunciaban el comienzo de la guerra popular prolongada.

Pero Munk era todavía más radical. En el páramo del mundo contemporáneo, sin ilusión y sin esperanza, donde ya no hay ficciones sociales poderosas ni alternativas al statu quo, había optado -como Alonso Quijano- por creer en la ficción. Era una suerte de Quijote que primero lee furiosa e hipnóticamente las novelas y luego sale a vivirlas (Piglia, El camino de Ida 232-233) ${ }^{14}$.

En sus Diarios, también se dirige a ese grupo con cierta ironía:

Por eso yo estoy transcribiendo mis diarios, porque quiero que sepan que hoy, a los setenta y tres años, sigo pensando lo mismo, criticando las mismas cosas que criticaba cuando tenía veinte años. Ahora estoy rodeado de conversos que cambian de idea cada temporada para adaptarse al sentido común general. Han abandonado una y otra vez sus convicciones y sus bibliotecas, mientras que yo sigo fiel a mis ideas y, de este modo de leer mis cuadernos -si los publico-podrán saber, o adivinar, o imaginar lo que ha sido mi vida (Piglia, Años de formación 357).

Las huellas que Piglia ha dejado en cada una de estas publicaciones demuestran que las operaciones críticas de la llamada Nueva Izquierda fueron tan extraordinarias en su capacidad para construir -o reconstruir-el campo intelectual de Argentina que va de los sesenta hasta nuestros días, que ese discurso que forjaron sus miembros desde una conciencia colectiva ha sido legitimado por la crítica literaria posterior. Al final, Piglia y sus compañeros de viaje han logado su objetivo: la constitución de una hegemonía cultural a través de lo que De Diego ha denominado "una crítica de la crítica", donde los colaboradores son al mismo tiempo sujeto y objeto del discurso crítico ("Los intelectuales" 412). Así también lo había definido Piglia en 
su diario de 1969: "estamos en la época de la crítica de la crítica crítica" (Los años felices 143). Aquella época, marcada por la intensa actividad de un colectivo en las revistas argentinas Los Librosy Punto de Vista, es el inicio de un proyecto escritural mucho más complejo y menos lineal que la simple referencia a sus compañeros de generación, pero que, sin duda, debemos entender como la base sobre la que se sustenta el sistema Piglia. Un sistema donde las posiciones del autor y del lector se imbrican en una red de relaciones en que la linealidad de la tradición queda demolida. Por tanto, para analizar dicho sistema en todas sus dimensiones es necesario atender a una permanente producción ensayística -no solo en estas revistas-, a la escritura de sus diarios, a su idea de la traducción o la manera en que asume la docencia, entre otros. Quizá, si su obra culmen -Los diarios de Emilio Renzi- ha sido escrita, como él mismo declara, para eternizar y resistir unos años de aguda actividad literaria, cultural y política que nunca regresarán, un nuevo acercamiento a su obra a través del concepto de nostalgia y utopía pueda abrir nuevos modos de leer su obra.

\section{BIBLIOGRAFÍA}

Álvarez, Emiliano. “Tiempo contemporáneo: una editorial de la Nueva Izquierda”. Políticas de la Memoria: anuario de investigación e información del Cedinci 13, 2012-2013, pp. 143-55.

"La revista Literatura y Sociedad: Entre la guerrilla, el marxismo y la crítica literaria ¿Un caso único y ejemplar?”. Américalee: el portal de publicaciones latinoamericanas del Cedinci, 2016.

Berg, Edgardo. Ricardo Piglia, un narrador de historias clandestinas. La Plata, Estanislao Balder, 2003.

De Diego, José Luis. ¿Quién de nosotros escribirá el Facundo? Intelectuales y escritores en Argentina (1970-1986). La Plata, Ediciones Al Margen, 2001.

"Los intelectuales y la izquierda en la Argentina (1955-1975)". Historia de los intelectuales en América Latina. Vol. 2. Los avatares de la ciudad letrada en el siglo XX. Carlos Altamirano (ed.), Buenos Aires, Katz Editores, 2008, pp. 395-416.

"La narrativa de Ricardo Piglia: figures retóricas y cuestiones de género". Anclajes 18, 2014, pp. 1-12.

DRUCAROFF, ElSA. "La narración gana la partida". Historia crítica de la literatura argentina. Vol. 11. Noé Jitrik (ed.), Buenos Aires, Emecé, 2010.

Falcón, Alejandrina. "Traducir, aclimatar, argentinizar: la importación literaria en 1969". Cuadernos Líricos 15, 2016, pp. 1-17. 
Fornet, JoRge. El escritor y la tradición: Ricardo Piglia y la literatura argentina. Buenos Aires, Fondo de Cultura Económica, 2007.

Fernández Cobo, Raquel. "Piglia en los 60: los inicios de una poética futura (Años de formación)". Revista Chilena de Literatura 98, 2018, pp. 183-207.

"Nostalgia, utopía y complot: la lectura como práctica colectiva en la obra de Ricardo Piglia”. Castilla: estudios de literatura 9, $\mathrm{N}^{\circ} 12,2021$, pp. 341-370.

García, Germán. "Leer a Gombrowicz”. Los Libros 2, agosto de 1969, p. 12.

GonzÁlez, Horacio. "Sobre Los Libros". Los Libros: edición facsimilar. Buenos Aires, Biblioteca Nacional, 2011, pp. 7-8.

LudMER, JosefinA. "La literatura abierta al rigor”. Los Libros, 9, 1970: 5.

OuBIÑA, DAVID. "Una lectura sobre Punto de Vista". Bazar Americano (web), 26 de marzo de 2004, consultado el 21 de noviembre de 2021, disponible en: http://www.bazaramericano. com/punto.php?msg=lectura

PAGNi, ANDREA. "Relecturas de Borges y Sur por la izquierda intelectual argentina desde los años ochenta: el caso de Punto de Vista". Actas del VII Congreso Nacional de Literatura Argentina. Facultad de Filosofía y Letras, Universidad Nacional de Tucumán, 1994, pp. 459-65.

Patiño, Roxana. "Intelectuales en transición: las revistas culturales argentinas (1981-1987)". Cuadernos de Recienvenido 4, 1997, pp. 5-34.

Piglia, Ricardo. "Heller, la carcajada liberal”. Los Libros. Buenos Aires, 1, 1969, pp. 11-12. "Una lectura de cosas concretas". Los Libros. Buenos Aires, 6, 1969, p. 3. "Nueva narrativa norteamericana". Los Libros. Buenos Aires, 11, 1970, pp. 11-14. "Clase media: cuerpo y destino". Nueva Novela Latinoamericana 2. Jorge Lafforgue (ed.), Buenos Aires, Paidós, 1972, pp. 350-362.

ET. AL. "Intelectuales y revolución, ¿conciencia crítica o conciencia culpable?”. Nuevos Aires 6, 1972, pp. 3-82.

"De la traición a la literatura". Los Libros. Buenos Aires, 27, 1971, p. 26.

"Mao Tse-Tung, práctica estética y lucha de clases". Los Libros. Buenos Aires, 25, 1972, pp. 22-25.

"Roberto Arlt, una crítica de la economía literaria". Los Libros. Buenos Aires, 29, 1973, pp. 22-27.

"La lucha ideológica en la construcción socialista". Los Libros. Buenos Aires, 35, 1974, pp. 4-9.

"Notas sobre Brecht”. Los Libros. Buenos Aires, 40, 1975, pp. 4-9.

“A mis compañeros Beatriz Sarlo y Carlos Altamirano". Los Libros. Buenos Aires, 40, 1977, p. 3.

"Hudson: ¿un Güiraldes inglés?" [firmado por Emilio Renzi]. Punto de Vista. Buenos Aires, 1, 1978, pp. 23-24.

"Ideología y ficción en Borges". Punto de Vista. Buenos Aires, 5, 1979, pp. 3-6.

"Notas sobre Facundo". Punto de Vista. Buenos Aires, 8, 1980, pp. 15-18. 
Respiración artificial. Barcelona, Anagrama, 2001.

Blanco nocturno. Barcelona, Anagrama, 2010.

El camino de Ida. Barcelona, Anagrama, 2013.

Los diarios de Emilio Renzi: años de formación. Barcelona, Anagrama, 2015.

Los diarios de Emilio Renzi: los años felices. Barcelona, Anagrama, 2016.

Los diarios de Emilio Renzi: un día en la vida. Barcelona, Anagrama, 2017.

Rosa, Nicolás. "Nueva novela latinoamericana, ¿nueva crítica?”. Los Libros, 1, 1969, p. 6.

"La crítica como metáfora"”. Los Libros. Buenos Aires, 2, 1969, p. 4.

Artefacto. Rosario, Beatriz Viterbo, 1992.

El arte del olvido y tres ensayos sobre mujeres. Buenos Aires, Beatriz Viterbo, 2004.

Sarlo, Beatriz. "Los dos ojos de Contorno". Punto de Vista 13, 1981, pp. 3-8.

"Sobre la vanguardia, Borges y el criollismo". La crítica literaria contemporánea.

Buenos Aires, CEAL, 1983, pp. 127-171.

“Intelectuales: Escisión o mimesis". Punto de Vista 25, 1985, pp. 20-32.

"El saber del texto". Punto de Vista. Buenos Aires, 26, 1986 6-8.

Somoza, Patricia y Elena Vinelli. "Para una historia de Los Libros". Los Libros: edición facsimilar. Buenos Aires, Biblioteca Nacional, 2011.

VV. AA. Los Libros: edición facsimilar. 4 vol. Buenos Aires, Biblioteca Nacional Mariano Merano, 2011. 